\title{
An Extremely Rare Combination: Pneumopericardium, Pneumoperitoneum, and Subcutanous Emphysema-A Case Report
}

Melek Zekiye Uluçam

To view enhanced content go to www.cardiologytherapy-open.com

Received: September 11, 2012 / Published online: December 1, 2012

(c) The Author(s) 2012. This article is published with open access at Springerlink.com

\section{ABSTRACT}

Pneumopericardium, an accumulation of air in the pericardial cavity, occurs very rarely as compared to pneumothorax and pneumomediastinum. Clinical presentation is variable, patients are frequently asymptomatic, and mild cases usually resolve spontaneously. However, it may lead to pericardial tamponade, which requires rapid diagnosis and treatment that can be lifesaving. The traditional diagnostic, simple method of diagnosis is via an upright chest X-ray. Typical findings can be detected and a differential diagnosis can be made between pneumomediastinum and pneumopericardium. Echocardiography and chest computed tomography scans can also support the

M. Z. Uluçam (ه)

Cardiology Department, Baskent University School of Medicine, Ankara, Turkey

e-mail: melekulucam@gmail.com

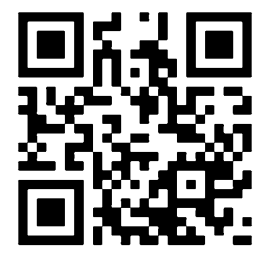

Enhanced content for this article is

available on the journal web site:

www.cardiologytherapy-open.com diagnosis. Only one case of pneumopericardium after surgical pericardiotomy has been reported in the literature so far. In this case report, iatrogenic pneumopericardium, which resolved spontaneously after surgical pericardiotomy, was reported in a 19-year-old patient who had a rejected liver transplantation, and had liver and kidney failure with pericardial tamponade. In this case, pneumopericardium was accompanied by pneumoperitoneum and subcutaneous emphysema; an extremely rare combination.

Keywords: Cardiology; Imaging; Intervention; Pneumopericardium; Pneumoperitoneum; Subcutaneous emphysema; Surgical pericardiotomy

\section{INTRODUCTION}

Pneumopericardium, an accumulation of air in the pericardium, develops due to several specific but rare reasons. It is less common than pneumothorax and pneumomediastinum [1, 2]. Patients with pneumopericardium are frequently asymptomatic, but depending on the amount and speed of accumulation of the 
air, cardiac tamponade and cardiogenic shock may occur. Thus, if a clinician suspects a patient has this condition, it must be urgently diagnosed. Pneumopericardium can be diagnosed by an upright chest X-ray within minutes. Treatment depends on the clinical severity. This report describes a case of pneumopericardium accompanied by pneumoperitoneum and subcutaneous emphysema which occured during the treatment of massive pericardial effusion in a patient with a rejected liver transplantation and kidney failure. The diagnosis and treatment of pneumopericardium will also be discussed, with a brief review of the literature.

\section{CASE REPORT}

A 19-year-old male patient with a rejected liver transplant and chronic liver and renal failure was admitted due to treatment-resistant ascites and recurrent variceal bleeding. A transjugular intrahepatic portosystemic shunt was applied to reduce portal pressure. The patient's clinical status improved, ascites decreased, and variceal bleeding did not recur for 3 months.

Three months later, hepatic encephalopathy and massive pericardial effusion developed, which was confirmed by an upright chest X-ray (Fig. 1) and echocardiography. Despite frequent hemodialysis over 7 days, there was no reduction in the amount of pericardial fluid, and cardiac tamponade developed. A pericardial tube insertion was applied subxiphoidally by surgical method and 3,500 cc pericardial fluid was drained. During the procedure, a pericardial fluid sample was taken and a biopsy was performed. Providencia stuarti was isolated and the pathologic diagnosis was acute nonspecific pericarditis.

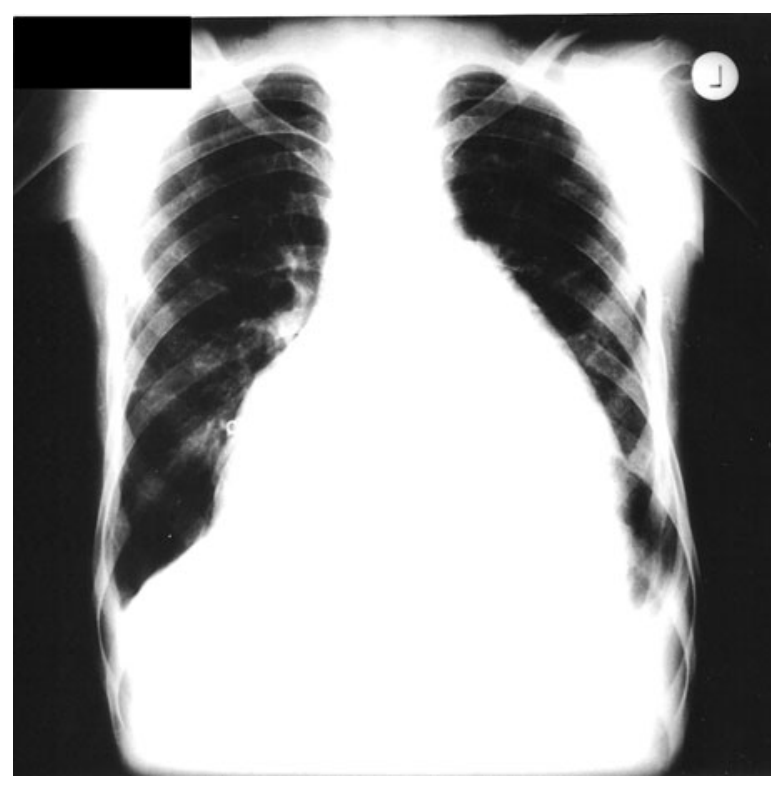

Fig. 1 Massive pericardial effusion seen on chest X-ray

The day after the pericardial tube insertion, the patient's heart sounds were silent and a new pericardial friction rub was heard. There was crepitus on palpation around the pericardial tube entry point and hemodynamic status was normal. An image of the patient's heart could not be obtained via echocardiograpy, and so an upright chest X-ray image was taken and, subsequently, massive pneumopericardium was diagnosed (Fig. 2). There was also pneumoperitoneum, which can be clearly observed under right hemidiaphragm (Fig. 2, arrowed).

In chest tomography, there was no pericardial effusion but there was a massive accumulation of air in the pericardial cavity. Pericardial thickening was moderate and thought to be secondary to pericarditis. In addition, there was the appearance of air and liquid (i.e., subcutaneous emphysema) at the drainage catheter entry point on the anterior chest wall. The pericardiotomy system was checked. There was a defect at the tube connection system. This 


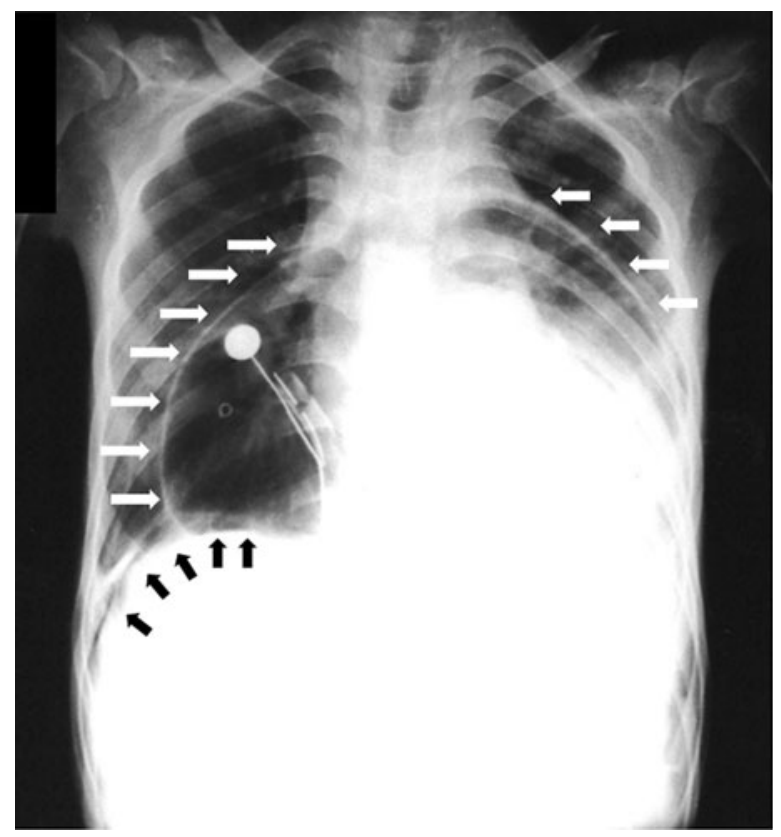

Fig. 2 Pneumopericardium and pneumoperitoneum following pericardial tube insertion. Pneumopericardium is represented with white arrows and pneumoperitoneum (air under right hemidiaphragm) is represented by the black arrows

caused air to fill into pericardial space. Defect of the connection system was repaired. There was no hemodynamic instability and a clinical decision was made to follow the patient's clinical symptoms without any futher intervention.

The next day, the pneumopericardium decreased (verified by chest X-ray) and the patient's pericardial tube was removed (Fig. 3). Pneumoperitoneum and subcutaneous emphysema also decreased. The following day, pneumopericardium, pneumoperitoneum, and subcutaneous emphysema had completely resolved. The patient's clinical condition improved gradually and the patient was discharged.

The patient was rehospitalized 1 month later for massive bilateral pleural effusion and treated by thoracentesis. The pleural effusion resolved completely. However, 2 weeks later

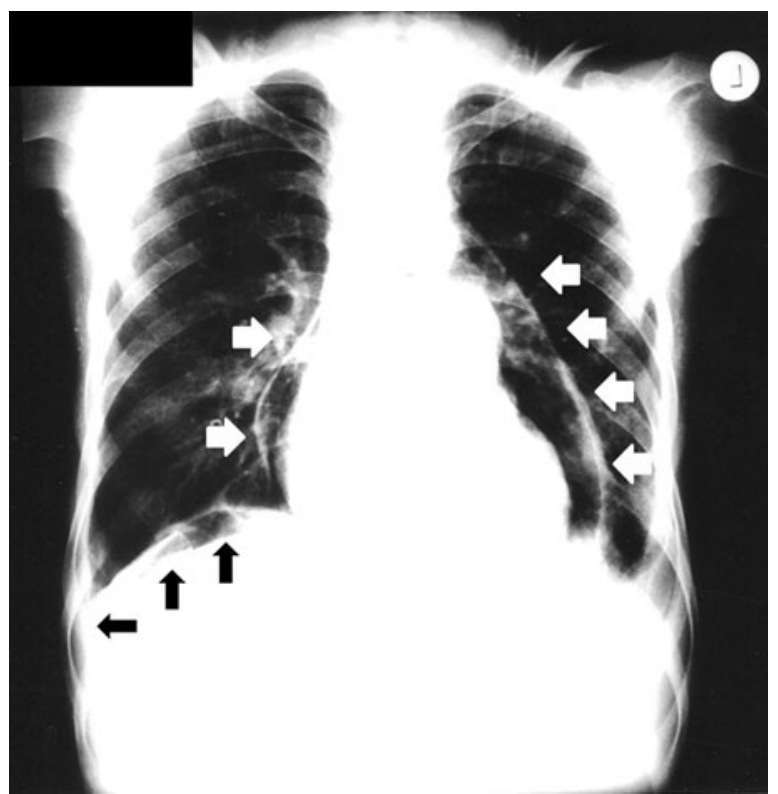

Fig. 3 Pneumopericardium in resolution phase after removing a pericardial tube. Pneumopericardium is represented by the white arrows. There is still air under the patient's right hemidiaphgram (black arrows)

the patient died due to liver and kidney failure.

\section{DISCUSSION}

\section{Methods of Pericardial Effusion Drainage}

Symptomatic pericardial effusions can be treated using several methods. The most frequently used methods are percutaneous pericardial drainage (pericardiocentesis) and surgical drainage of the pericardium (surgical pericardiotomy).

Pericardiocentesis can be done under emergent conditions and corrects symptoms associated with pneumopericardium without surgical incision and general anesthesia; however, it cannot provide permanent relief from the condition. Markiewicz et al. [3] and Wong et al. [4] demonstrated that recurrent tamponade occurred in $83 \%$ and $32 \%$ 
(respectively) of patients that had undergone pericardiocentesis. This discrepancy may be due to the different patient ratios with malign pericardial effusion, which has a high recurrence rate, between studies. Serious complications were reported in $15 \%$ of the patients, including cardiac chamber laceration, intercostal vessel injury, pneumothorax, ventricular tachycardia, bacteremia, and death. Cardiac chamber laceration can be diagnosed by ventricular fibrillation followed by acute circulatory collapse. Hemothorax (which is caused by intercostal vessel injury) and pneumothorax, due to pleural trauma, can be diagnosed by the presence of acute respiratory distress; a chest X-ray is helpful for diagnosing both conditions. Bacteremia is diagnosed with clinical findings like fever and chills and positive blood cultures. Following echocardiography and fluoroscopy, the incidence of complications decreases significantly [5]. Recent studies have showed that the incidence of major complications is $1.2-1.6 \%[6,7]$.

In current medical practice, standard electrocardiographic monitoring is mandatory during a pericardiocentesis. An electrogram recorded via a lead attached to the puncture needle can be used to inform the operator that the needle is in contact with myocardium, but it was found to be time consuming and unnecessary [8]. The complication rate of pericardiocentesis is severely reduced after fluoroscopic and echocardiographic guidance of needle location during the process [5]. Advantages of echocardiography, such as ease of monitoring needle position, identification of the effusion properties, no exposure to radiation, and a chance to apply contrast echocardiography by agitated saline during procedure, makes it very attractive as a guide for pericardiocentesis [9]. However, it can complicate the procedure and compromise aseptic technique. The weight of evidence versus opinion appears to be in favor of echocardiographic guidance and monitoring of pericardiocentesis [10]. Thus, it should be used whenever possible [10].

Surgical pericardiotomy and drainage is less commonly performed than pericardiocentesis. It can be done under local or general anesthesia [11]. It is known as pericardiotomy, pericardiostomy, and "window" pericardiectomy, and is generally carried out at the subxiphoid region. A pericardial "window" can be made with open surgery or videoassisted thoracoscopy. It has the ability to drain the pericardial cavity completely and a pericardial biopsy can also be taken during the process. The incidence of complications are lower than percutaneous pericardial catheter drainage and retrospective studies have demonstrated minimal surgical morbidity and mortality [12-14]. In a study of 305 patients with pericardial effusion that underwent a subxiphoid pericardiotomy, complications associated with surgical pericardiotomy included operative death (2.3\%), myocardial infarction $(0.7 \%)$, pulmonary embolism (1\%), renal failure $(4.3 \%)$, pneumonia (3.6\%), reintubation (6.2\%), pleural effusion (1.3\%), pneumothorax (2\%), and wound infection (1\%) [11]. Percutaneous catheter drainage has been reported and resulted in a recurrence rate of $0-30 \%$, while open subxiphoid drainage resulted in a recurrence rate of $0-9.1 \%$ $[15,16]$. Surgical pericardiotomy is often preferred if pericardial effusion has reaccumulated after prior percutaneous drainage; reaccumulation is probable, if there is loculated pericardial effusion, or a biopsy of the pericardium is desired for diagnostic purposes. Additionally, the procedure is the preferred option if the patient has a coagulopathy, large pericardial effusions, and high morbidity. 


\section{Clinical Features of Pneumopericardium}

Pneumopericardium is extremely rare and can be caused by physical trauma to the pericardium (e.g., nonpenetrating and penetrating thorax trauma) [17], barotrauma (e.g., mechanical ventilation) [18], acute asthma attack, coughing, Heimlich and Valsalva maneuvers, pregnancy and labor, and fistulas of the pericardium (e.g., thorax tumors, infections, and abscesses). Rarely, it may develop due to pericarditis caused by spontaneous gas-producing microorganisms, invasive procedures (e.g., thoracotomy, tracheostomy, tracheostomy closure [19], thoracentesis, pericardiocentesis [20-23], surgical pericardiotomy [24], endomyocardial biopsy [1], pacemaker insertion [25]), complications of cardiac resynchronization therapy [26], or Boerhaave syndrome (e.g., spontaneous esophageal wall perforation) [27].

\section{Diagnosis of Pneumopericardium}

Upon physical examination, heart sounds are muffled and there is often shifting precordial tympany and evidence of Hamman's sign, a crunching sound that can be heard with each heartbeat due to compression or replacing of air in the pericardial cavity [28]. If pericardial tamponade develops, pulsus paradoxus can be seen. Electrocardiogram findings may detect signs of pericarditis, such as ST segment depression/elevation, T-wave inversion, and low voltage [29]. Due to the large amount of air between the heart and chest wall, the echogenicity of the heart decreases and echocardiography of the heart becomes difficult and is sometimes undetectable [30]. Another sign ("air gap") consists of a loss of the M-mode and two-dimensional image of the heart during the systolic phase of each cardiac cycle [31, 32].

In hydropneumopericardium, swirling bubbles are formed, possibly from the continuous shaking of the air-fluid surface caused by heart activity $[30,33]$. In some cases, the air-fluid interface can be directly demonstrated in two-dimensional echocardiography [30].

The most helpful diagnostic test for this condition is an upright chest X-ray $[1,20]$. Pneumopericardium is recognized by air lucency outlining the heart and separated from the lung fields by a strip of pericardium. Sometimes, an air-filled and stretched pericardium is found. If pneumopericardium is accompanied by pericardial effusion, an airfluid level surrounding the heart can be seen on a chest X-ray [20]. In pneumopericardium, the highest level of air is at the aorta and pulmonary artery in the thorax [21]. If the air collection extends longitudinally to include more cranial levels, the diagnosis is pneumomediastinum [22]. Pericardial, but not mediastinal, air will shift with changes in position for decubitus films [34]. Mirvis et al. [35] described a decrement in cardiothoracic ratio with pneumopericardium and diminishing cardiac silhouette on serial chest X-ray films.

Pneumopericardium diagnosis can also be supported with a chest computed tomography (CT) scan. Characteristics of pneumopericardium as seen on a CT scan are the heart being partially, or completely, surrounded by air, with the pericardium sharply outlined by air density [36].

\section{Treatment of Pneumopericardium}

There is no consensus regarding treatment of pneumopericardium and the clinical course is 
highly variable. Treatment depends on etiology and clinical severity, which is determined by the amount and speed of the of the accumulation of air in the pericardium [33]. Hypotension, radiographic intrapericardial air, and absent alternative causes of shock constitute the diagnosis of fatal pericardial tamponade due to pneumopericardium [37]. However, usually pneumopericardium heals spontaneously within a few days [20]. If there is no hemodynamic imbalance, clinical monitoring of patients with pneumopericardium waiting for absorption of air is possible. On the contrary, if pericardial tamponade develops, pericardiocentesis or surgically closing the channel between air and pericardium should be performed urgently [20].

\section{Treatment of Pneumoperitoneum}

Pneumoperitoneum, or the presence of free air in the abdominal cavity, is often (in $>90 \%$ of cases) indicative of abdominal organ perforation and frequently requires emergency surgery. But, if signs of peritoneal irritation, fever, leukocytosis, and peritonitis are absent and the clinical status does not support organ perforation, laparotomy should be avoided [38]. Nonsurgical pneumoperitoneum constitutes as many as $10-15 \%$ of patients with pneumoperitoneum and can resolve spontaneously. The most frequent causes of pneumoperitoneum are intraabdominal, thoracic, gynecologic, or iatrogenic [38]. For example, subxiphoid pericardiotomy is a situation which can cause pneumoperitoneum due to incomplete connections of the pericardiotomy system.

\section{Comment About this Case}

In the present case study, abnormal air flow in the pericardial sac was probably due to air leakage to the tube drainage system with faulty connections. This was accompanied by pneumoperitoneum and subcutaneous emphysema related with abdominal and skin trauma caused by the pericardiotomy tube. In the literature, only one case of pneumopericardium after surgical pericardiotomy has been reported so far [24], and the fact that this case was accompanied by pneumoperitoneum and subcutaneous emphysema makes it unique.

\section{CONCLUSION}

In summary, as shown in the case study, surgical pericardiotomy can cause pneumopericardium, pneumoperitoneum, and subcutaneous emphysema. Pneumopericardium is a very rare disease but it can easily be diagnosed using a chest X-ray, a relatively inexpensive, readily applicable test. As these conditions can occasionally have an fatal clinical course, diagnosis with an upright chest X-ray can be lifesaving and will have advantages in clinical applications.

\section{ACKNOWLEDGMENTS}

Dr. Ulucam is the guarantor for this article, and takes responsibility for the integrity of the work as a whole.

Conflict of interest. The author declares no conflicts of interest.

Open Access. This article is distributed under the terms of the Creative Commons Attribution Noncommercial License which permits any noncommercial use, distribution, and reproduction in any medium, provided the original author(s) and the source are credited. 


\section{REFERENCES}

1. Celik T, Iyisoy A, Kursaklioglu H, Gunay C, Yuksel UC, Isik E. A case of pneumopericardium following endomyocardial biopsy. J Card Surg. 2007;22:519-21.

2. Pişkin I, Ozmen S, Teoman P, Arslan Z. Two pediatric cases of spontaneous pneumomediastinum and subcutaneous emphysema during status asthmaticus. Turk Klinikleri J Med Sci. 2005;25:581-4.

3. Markiewicz W, Borovik R, Ecker S. Cardiac tamponade in medical patients: treatment and prognosis in the echocardiographic era. Am Heart J. 1986;111:1138-42.

4. Wong B, Murphy J, Chang CJ, Hassenein K, Dunn M. The risk of pericardiocentesis. Am J Cardiol. 1979;44:1110-4.

5. Maisch B, Seferovic PM, Ristic AD, et al., Task Force on the Diagnosis and Management of Pericardial Diseases of the European Society of Cardiology. Guidelines on the diagnosis and management of pericardial diseases executive summary; The Task force on the diagnosis and management of pericardial diseases of the European Society of Cardiology. Eur Heart J. 2004;25:587-610.

6. Tsang TS, Freeman WK, Barnes ME, Reeder GS, Packer DL, Seward JB. Rescue echocardiographically guided pericardiocentesis for cardiac perforation complicating catheter-based procedures. The Mayo Clinic experience. J Am Coll Cardiol. 1998;32:1345-50.

7. Tsang TS, Barnes ME, Hayes SN, et al. Clinical and echocardiographic characteristics of significant pericardial effusions following cardiothoracic surgery and outcomes of echo-guided pericardiocentesis for management: Mayo Clinic experience, 1979-1998. Chest. 1999;116:322-31.

8. Krikorian JG, Hancock EW. Pericardiocentesis. Am J Med. 1978;65:808-14.

9. Tsang TS, Enriquez-Sarano M, Freeman WK, et al. Consecutive 1127 therapeutic echocardiographically guided pericardiocenteses: clinical profile, practice patterns, and outcomes spanning 21 years. Mayo Clin Proc. 2002;77:429-36.

10. Cheitlin MD, Armstrong WF, Aurigemma GP, et al. ACC/AHA/ASE 2003 guideline update for the clinical application of echocardiography: summary article: a report of the American College of Cardiology/American Heart Association Task Force on Practice Guidelines (ACC/AHA/ASE Committee to Update the 1997 Guidelines for the Clinical Application of Echocardiography). Circulation. 2003;108:1146-62.

11. Sarigul A, Farsak B, Ates MS, Demircin M, Pasaoglu I. Subxiphoid approach for treatment of pericardial effusion. Asian Cardiovasc Thorac Ann. 1999;7:297-300.

12. McDonald JM, Meyers BF, Guthrie TJ, Battafarano RJ, Cooper JD, Patterson GA. Comparison of open subxiphoid pericardial drainage with percutaneous catheter drainage for symptomatic pericardial effusion. Ann Thorac Surg. 2003;76:811-5.

13. Allen KB, Faber LP, Warren WH, Shaar CJ. Pericardial effusion: subxiphoid pericardiostomy versus percutaneous catheter drainage. Ann Thorac Surg. 1999;67:437-40.

14. Moores DW, Allen KB, Faber LP, et al. Subxiphoid pericardial drainage for pericardial tamponade. J Thorac Cardiovasc Surg. 1995;109:546-51.

15. Sugimoto JT, Little AG, Ferguson $M K$, et al. Pericardial window: mechanism of efficacy. Ann Thorac Surg. 1990;50:442-5.

16. Girardi LN, Ginsburg RJ, Burt ME. Pericardiocentesis and intrapericardial sclerosis: effective therapy for malignant pericardial effusions. Ann Thorac Surg. 1997;64:1422-7.

17. Macgoey P, Schamm M, Degiannis E. Tension pneumopericardium: case report. Ulus Travma Acil Cerrahi Derg. 2010;16:477-9.

18. Just B, Ledon S Jr, Lejean F Jr, Boutiere JP, Mateu P. Iatrogenic tension pneumopericardium in a patient with posttraumatic acute respiratory distress syndrome. Ann Fr Anesth Reanim. 2012;31:e59-60.

19. Koloutsos G, Barbetakis N, Kirodimos E, Samanidis G, Paliouras D, Vahtsevanos K. Pneumopericardium following tracheostomy closure. Tuberk Toraks. 2009;57:205-7.

20. Ozerkan F, Bilgin M, Oktem MS, Alkan MB. Pneumopericardium after pericardiocentesis: a case report. Turk Kardiyol Dern Ars. 2011;39:697-700.

21. Varol E, Ozaydin $M$, A ğçal C. Iatrogenic pneumopericardium. Anadolu Kardiyol Derg. 2006;6:298.

22. Mullens W, Dupont $M$, De Raedt $H$. Pneumopericardium after pericardiocentesis. Int J Cardiol. 2007;118:e57.

23. Methachittiphan N, Boonyaratavej S, Kittayarak C, et al. Pneumohydropericardium with cardiac 
tamponade after pericardiocentesis. Heart. 2012;98:93.

24. Marijon E, Jani D, Aubert S. Unusual chest radiograph after surgical pericardiotomy. Tex Heart Inst J. 2007;34:256-7.

25. O’Neill R, Silver M, Khorfan F. Pneumopericardium with cardiac tamponade as a complication of cardiac pacemaker insertion one year after procedure. J Emerg Med. 2012;43:641-4.

26. Baranchuk A, Simpson CS, Pinto S, Redfearn DP. Pneumopericardium after attempted left ventricular lead insertion. Can J Cardiol. 2008;24:e56.

27. Kurt A, Karaoğlanoğlu M, Tanrıvermiş A, İpek A. Boerhave's Syndrome: Multislice CT findings: Case report. Türkiye Klinikleri J Gastroenterohepatol. 2011;18:38-41.

28. Hamman, L.: Spontaneous mediastinal emphysema. Bull Johns Hopkins Hosp. 1939;64:1-21.

http://www.medicalarchives.jhmi.edu/jhbullindex/ jhhb-drv.htm (2012). Accessed Nov 8, 2012.

29. Brander L, Ramsay D, Dreier D, Peter M, Graeni R. Continuous left hemidiaphragm sign revisited: a case of spontaneous pneumopericardium and literature review. Heart. 2002;88:e5.

30. Antonini-Canterin F, Nicolosi GL, Mascitelli L, Zanuttini D. Direct demonstration of an air-fluid interface by two-dimensional echocardiography: a new diagnostic sign of hydropneumopericardium. J Am Soc Echocardiogr. 1996;9:187-9.
31. Reid CL, Chandrarama Echocardiographic

AN, Icawanishi D. detection of pneumomediastinurn and pneumo-pericardium: the air gap sign. J Am Coll Cardiol. 1983;1:916-21.

32. Bedotto IB, McBride W, Abraham M, Taylor AL. Echocardiographic diagnosis of pneumopericardium and hydropneumopericardium. J Am Soc Echocardiogr. 1988;1:359-61.

33. Yuce M, Sari I, Davutoglu V, Ozer O, Usalan C. Bubbles around the heart: pneumopericardium 10 days after pericardiocentesis. Echocardiography. 2010;27:E115-6.

34. Cummings RG, Wesly RL, Adams DH, Lowe JE. Pneumopericardium resulting in cardiac tamponade. Ann Thorac Surg. 1984;37:511-8.

35. Mirvis SE, Indeck M, Schorr RM, Diaconis JN. Posttraumatic tension pneumopericardium: the "small heart" sign. Radiology. 1986;158:663-9.

36. Morimatsu Y, Kawano F, Aizawa H. Pneumopericardium following rupture of the oesophagus. Lancet. 2006;368:1991.

37. Capizzi PJ, Martin M, Bannon MP. Tension pneumopericardium following blunt injury. J Trauma. 1995;39:775-80.

38. Karaman A, Demirbilek S, Akin M, Gürünlüoglu K, Irşi C. Does pneumoperitoneum always require laparotomy? Report of six cases and review of the literature. Pediatr Surg Int. 2005;21:819-24. 